\title{
VALERIA CAVAZZINO
}

Università degli Studi di Napoli "L'Orientale"

\section{Informar y contar comunicación y narración en la escritura periodística de Jorge Carrión}

\author{
Reporting and narrating: Communication and storytelling \\ in Carrión's journalistic writing
}

\begin{abstract}
In recent years, due to the rise of cultural productions through different media, an increase in the number of journalistic publications of hybrid texts has been observed, which results from the fusion of the narrative and informative functions. The spaces traditionally devoted to different types of journalistic texts which - apart from those merely informative, may include cultural-related and opinion articles - make possible the appearance of articles which distinguish themselves trough entailing both characteristics. Therefore, this paper analyses two articles written by J. Carrion and published in the Spanish edition of The New York Times in 2018. The articles will be scrutinised in relation to the narrative and essayistic works of the author. We illustrate some characteristics of what is generally referred to as narrative journalism, as defined by Herrscher (2012) and Casals Carro (2005), among others. This will allow us to trace a profile of the author, journalist and writer which is linked to the social environment and of his work.
\end{abstract}

KEY WORDS: chronicle, narration, journalism, interpretation, urban space.

\section{Introducción}

Muchos son los géneros periodísticos que se prestan a la contaminación literaria. Reportaje, crónica, artículo, nota, análisis, ensayo, relato de viajes o artículo de costumbres revelan el potencial híbrido que los distingue para redefinirse y colocarse en el marco del „periodismo narrativo”. Diversos estudios, procedentes del campo de la periodística y de la crítica literaria, se han fijado en el análisis de las relaciones entre la literatura y el periodismo y nos proporcionan 
la base teórica de este estudio enfocado, más bien, en un género, la crónica, en su máxima tensión narrativa, según el modelo practicado por el escritor barcelonés Jorge Carrión.

La labor periodística de Jorge Carrión abarca muchos años, varios medios y, sobre todo, códigos diferentes y variados.

Su colaboración en prensa se inicia con las crónicas publicadas por el periódico $A v u i$ y la participación en el consejo de redacción de varias revistas, como Lateral, Letras libres, La Vanguardia (para la sección „Cultura”) y Quimera. Entretanto, no deja de escribir obras de „ficción” y ensayos críticos, de editar antologías y, al mismo tiempo, dar clases y conferencias en prestigiosos centros académicos y culturales internacionales. En la actualidad, sigue publicando en los diarios y revistas mencionadas, a las que añadimos El País, la edición española de The New York Times y en las plataformas digitales de Jot Down, Anfibia, solo por citar unos ejemplos. Su perfil profesional refleja la versatilidad y la diversificación implícita a su producción escrita. Carrión suele moverse entre los géneros del periodismo y de la literatura, proponiendo libros y artículos, series narrativas y periodísticas, tan peculiares que resulta tan impactante como para tomarlo como modelo de estudio comprendido en el marco de las evoluciones del periodismo narrativo contemporáneo.

Este estudio se propone, por tanto, analizar las estrategias compositivas y estructurales presentes en dos artículos publicados entre el 11 y el 18 de febrero de 2018 en la edición española de The New York Times y que tienen como motivo narrativo y crítico la ciudad de Barcelona; el propósito del estudio es detectar los elementos de cohesión narrativa entre las técnicas propias del periodismo y de la literatura. En particular, el estudio enfoca las peculiaridades expresivas en uso propias de cierta práctica periodística que hace referencia al género de la opinión. Por otro lado, se aportarán consideraciones relativas al estudio de las tendencias y de las características del periodismo narrativo, ámbito en el que la presencia de Jorge Carrión se impone a la atención siendo una de las firmas más influyentes hoy en día.

\section{Hacia el periodismo literario: rutas narrativas}

Antes de empezar con el análisis textual de la serie de artículos que han sido seleccionados a partir de consideraciones temáticas y estructurales, es oportuno trazar un breve recorrido biográfico del autor.

Jorge Carrión nace en Tarragona en 1976 y muy pronto se muda con su familia a Mataró, ciudad en la que se cría y comienza los estudios. En estos 
años se inicia su vocación literaria y, de hecho, a final de los ' 90 gana unos premios municipales de cuento. A partir de la época universitaria, durante el curso de su primer doctorado en literatura española contemporánea en la Universad de Barcelona (UB), su actividad narrativa sigue muy viva. La primera fase de su producción está sutilmente conectada con las vivencias de viajes llevados a cabo durante la época de su segundo doctorado en literatura comparada por la Universidad Pompeu Fabra: Ene (2001), La brújula (2006), una recopilación de crónicas y ensayos vinculados con sus viajes americanos, y Australia. Un viaje (2008). Pero hay que destacar una parte de su trabajo que no tiene cabida en la creación literaria propiamente dicha y que sí contribuye a completar su perfil de ensayista y crítico de la nueva ola. Textos como Teleshakespeare (2011), Mejor que ficción. Crónicas ejemplares (2012) - que es una antología de textos de autores hispanoamericanos presentados por Carrión, quien procura enmarcarlos teóricamente bajo el sello de la no ficción literaria- y Librerias (2013) - ensayo en el que su autor traza un mundo intraliterario rico de citas, plasmado en torno a las miles de librerías visitadas pobladas por libreros devotos al oficio-, confirman su presencia exitosa en el ámbito de estudios socioculturales más sostenidos hoy en día. De hecho, ya con Teleshakespeare había adquirido atención por parte de la crítica por ser considerado un ensayo pionero en su enfoque multimedial y, en particular, teleserial. Las huellas de su afición a las teleseries se hacen evidentes en su obra literaria, pero de forma evolucionada en sentido más creativo que crítico, como demuestra, por ejemplo, la novela Los muertos.

Entre las líneas de esta breve presentación del autor y de su producción, quedan en transparencia los volúmenes propiamente narrativos que conforman la serie de Las Huellas, una tri/tetralogía, por cierto, en el sentido de que se trata de una colección de tres libros más uno: Los muertos (Literatura Modadori, 2010), Los huérfanos (Galaxia Gutenberg, 2014), Los turistas (Galaxia Gutenberg, 2015) y, finalmente, Los difuntos (Aristas Martínez, 2016). Esta última es una novela ilustrada por el artista Celsius Pictor y representa el epílogo (y también precuela) de la serie, concluyendo el proyecto narrativo de ciencia ficción inaugurado con Los muertos. La serie realiza un complejo juego de tránsito de códigos-lingüísticos, expresivos- de épocas y mundos distantes y, al mismo tiempo afines, en los que el autor narra las experiencias de los personajes en situaciones absurdas. La tendencia renovadora perpetuada por su producción narrativa insiste en la reformulación del diálogo entre cuento y nuevas realidades sociales y culturales; sin embargo, la estructura global de la serie narrativa se caracteriza por la fusión de géneros y de temas: ciencia-ficción, ensayo-ficción, relatos de viaje y narrativa fantástica que conforman el marco y el hilo narrativo de las tres novelas. En cuanto a los temas, es apreciable la recurrencia de motivos como la persecución, verdadera obsesión para el autor junto con la supervivencia y la redención, consideradas claves interpretativas siempre liga- 
das al viaje, gran macrotema que evoca el carácter cosmopolita y urbano de su literatura.

La relación entre tiempos y mundos distintos y distantes identifica el hilo conductor entre las narraciones de la serie: Los muertos, afirma Carrión, «es el centro de la trilogía. Ocurre entre el año 10 y 15 de nuestro siglo. Los huérfanos es un flash forward de las consecuencias de Los muertos y Los turistas es el origen posible de ese mundo» (SAInz Borgo, 2015). La huella, finalmente, se configura como el trait d'union entre las novelas y alude, de formas diferentes en cada una de las tres partes, a la superación del trauma individual o colectivo inserto en cada historia y presente en todas las dimensiones narrativas; es, en definitiva, el sostén estructural y temático que identifica la colección como una red textual, modelo de la renovación formal y sustancial de las corrientes narrativas contemporáneas.

Su pasaje por el mundo de la ficción no limita su índole crítica e investigadora. Tanto el ensayo como la crónica se confirman como elemento y espacio privilegiado de su labor. Su último trabajo colabora al cambio escenográfico de su producción: Barcelona. Libro de los pasajes (Galaxia Gutenberg, 2017) diseña una topografía social y literaria de la capital catalana (en)marcada por esas singulares construcciones y conceptos urbanísticos que llegan a ser definiciones de la conformación barcelonesa actual.

Si el tiempo y el espacio se definen como «los factores que rigen y delimitan el concepto de lenguaje periodístico» (CASAls CARRO, 2005: 375), ahora bien, quedémonos en el marco urbano para deslizar el perfil más puramente periodístico de Carrión, presentando una serie de artículos sobre los cuales me propongo llevar a cabo un análisis pormenorizado de los recursos y de las construcciones retóricas y estructurales del mensaje periodístico vehiculado por los textos objetos de estudio, bajo una perspectiva a la vez lingüística y narratológica. Junto a esto, se tendrán en cuenta dos modelos textuales más representados por un cómic periodístico Barcelona. Los vagabundos de la chatarra (Norma Editorial, 2015) y un ensayo, Barcelona. Libro de los pasajes, para deslizar un perfil autorial coherente y respetuoso con su variedad.

\subsection{Viajes e imágenes}

Los valores transmitidos por la obra del autor, en referencia a la parte más propiamente literaria en confrontación con la periodística, revelan la unidad simbólica y temática que la animan. El viaje, la exploración del espacio, geográfico e interior, condicionan y plasman la poética y la estética de su producción. La urgencia de anclarse al tejido urbano de procedencia, junto con la tensión de ir más allá de los límites convenidos, en un sentido real y metafórico, determinan las referencias de sus trabajos. De hecho, destacan los títulos de libros, colecciones 
de relatos al límite de la crónica (y al revés), así como narraciones largas, dedicados al cuento de sus propias experiencias de viajes: Crónica de viaje (Aristas Martínez, 2014), Norte es sur. Crónicas americanas (Debate Venezuela, 2009), La piel de La Boca (Libros del Zorzal, 2008), Australia. Un viaje (Berenice, 2008), GR-83 (edición de autor, 2007), La brújula (Berenice, 2006). El interés por comunicar a quien lee sus vivencias personales revela su propia voluntad de compartir el punto de vista de observación y de conducción del cuento que se hace, finalmente, pura crónica de viaje.

Personal y colectivo son conceptos que se disuelven a la hora de transmutar el código comunicativo mediante el cual Jorge Carrión entra en contacto con sus lectores. Su periodismo es narración, se fundamenta en el cuento y en la interpretación de los hechos a los que asiste en calidad de testigo participante para ofrecer, al fin y al cabo, un relato verosímil y contextualizado de la realidad observada.

El periodismo narrativo, escribía Herrscher, «es capaz de hacer algo más que transmitir la voz y el punto de vista del narrador. Puede llevarnos a las voces, las lógicas, las sensibilidades y los puntos de vista de los otros» (Herrscher, 2012: 30). En esta dirección, sus crónicas se configuran como una invitación a interpretar la realidad según perspectivas y recursos que proceden del ámbito literario y que se renuevan a través del canal comunicativo propio del periodismo, confiriendo más valor y autonomía al espacio específico del periodismo narrativo.

El periodismo narrativo, en este sentido, trata de reflejar el universo complejo que nos rodea. Y para ello se sirve de las llamadas figuras del discurso, esto es, las formas no convencionales de utilizar las palabras, de manera que, aunque se emplean con sus acepciones habituales, se acompañan de algunas particularidades fónicas, gramaticales o semánticas, que las alejan de su uso habitual, por lo que terminan por resultar especialmente expresivas (TIJERAS, 2013).

La selección de textos propone una valoración estilística y temática de las crónicas que tienen como motivo esencial o base narrativa la ciudad de Barcelona. El relato de una ciudad, de un espacio compartido pero vivido de forma subjetiva, se integra perfectamente en un formato, el periodístico en este caso, que bien expresa la voluntad del autor para comunicarse con los demás. Crónicas y registro cronístico protagonizan el interés de este estudio, que toma como modelos de análisis algunos textos periodísticos respaldados por un libro, Barcelona. Libro de los pasajes, un ensayo/crónica centrado en las posibles definiciones de qué es una ciudad mediante la exploración de una de sus partes constituyentes y, quizá, menos valoradas: los pasajes, «esas galerías cubiertas, esa sucesión de escaparates que se deslizaban por las entrañas de la ciudad» (CARRIón, 2017a: 13).

Así se lee en un momento dado de la narración, una interpretación del sentido adquirido por los pasajes para su propio visitador: 
[...] los pasajes son la muestra que extraigo con mis brocas anulares, mis testigos de todas las Barcelonas posibles, fragmentos vivos de una ciudad muy viva, regada desde siempre por savia y sangre y ríos subterráneos, puro futuro de huellas futuras.

CARRIÓN, 2017a: 130

La reciente publicación del libro mencionado puede considerarse el culmen de un proceso que le ha llevado al autor a reconocerse como parte de la ciudadanía barcelonesa, valor finalmente adquirido después de haberse instalado en la capital,

[...] una ciudad -escribe- [que] no es la mía. O no del todo. Yo no me crié aquí. En el 95\% de estas calles, de estos pasajes, no había estado hasta el momento en que decidí escribir este libro. Constituye una gran ventaja, esa distancia. [...] Me acerca a Benjamin, extranjero en París, pasajero de paso, pero sin su soledad, sin su tristeza, [...] sin su suicidio. Por suerte.

CARrIÓN, 2017a: 131

La voluntad de integración, de identificación con el espacio urbano demuestra toda la urgencia del escritor comprometido con su propia voluntad de explorar el territorio tan próximo, si no propiamente familiar. Pero salvaguardar el punto de vista significa revitalizar la distancia dada por no ser nativo, una ocasión que el autor no solo preserva sino que sigue valorando durante toda la excursión narrativa. En realidad, el interés por el contexto social y urbano de la capital catalana surge mucho antes, junto con la voluntad de llevar a la atención pública la existencia de vidas paralelas subterráneas. El contacto con la narración del espacio urbano de Barcelona está marcado por la elaboración de un proyecto que empezó a tomar vida en torno al 2012 en colaboración con el dibujante Sagar Forniés, y llevó a la publicación de Barcelona. Los vagabundos de la chatarra en 2015, una novela gráfica de no ficción. Para la realización de este cómic periodístico, Carrión se perfila como guionista, es el autor de los textos que acompañan a las viñetas estilizadas en directo por Sagar, apreciadas por ser «realmente espectacular y consigue transmitir la inmediatez de las entrevistas al mismo tiempo que reconstruye unos escenarios completamente fieles a la realidad» (blog de David Fernández de Arriba Historia y Cómic, 2015). Un año de documentación inaugura el camino hacia la toma de conciencia de un espacio físico, pero a la vez interior e interiorizado, que definen sus actuales intereses y preocupaciones narrativo-periodísticas. La inclusividad se presenta, de inmediato, como cifra creativa y estilística de su labor, como señala la presencia, por ejemplo, de los dos autores como personajes del cuento gráfico; la exploración de las periferias de la ciudad, en términos, por cierto, geográficos pero también humanos colaboran a la recreación de un universo intradiegético variado y esencialmente realista, en el que no se pierde, sino que adquiere más valor y potencia la carga documental del libro. 
Se asiste, en cambio, a dinámicas diferentes a la hora de evaluar su producción columnística. En los artículos, ya veremos, pasa algo diferente. Sus trabajos periodísticos se insertan en el ámbito de los campos del periodismo especializado, como el cultural y el narrativo. Crónicas, artículos y entrevistas son los géneros más cultivados por Jorge Carrión. Pero, aunque sería muy interesante profundizar en las estrategias narrativas propias de los dos libros citados, vamos a fijarnos en el caso de su única «serie» de crónicas aparecidas durante el mes de febrero de 2018, en la edición española del New York Times, y que tienen como objeto de argumentación la ciudad de Barcelona.

\section{Periodismo narrativo: entre información e interpretación}

La idea de comparar, o simplemente de componer un recorrido a base temático considerando una parte de la producción de Jorge Carrión, lleva a la coincidencia de presentar un estudio enfocado en dos crónicas narrativas, como se ha dicho, introducidos idealmente por dos textos más, representantes cada uno de una fórmula narrativa-periodística diferente: la alusión hace referencia al cómic periodístico, Barcelona. Los vagabundos de la chatarra, y al libro ensayo, Barcelona. Libro de los pasajes. Aprovechando también la publicación de la tercera edición de Barcelona. Los vagabundos de la chatarra, a comienzos de este año, destacamos la peculiaridad de la uniformidad temporal en la que aparecen estos títulos, guardando, al mismo tiempo, la excepcionalidad del cómic, que se configura como precursor de la fase narrativa que comentamos.

De este modo, el «modelo Barcelona» queda reflejado en sus textos como algo más que inclusivo, refiriéndose, al mismo tiempo, a temas globales y colectivos. Alude, por ejemplo, al nacionalismo o a aspectos marginales de la vida urbana, como en nuestro caso el de los chatarreros clandestinos, y registra zonas menos conocidas de la capital, como muestran, efectivamente, los pasajes explorados y presentados en el Libro de los pasajes. Momento crucial y referente del interés particular de Carrión y de sus narraciones es la crisis que aparece como el vínculo que pone en relación el ensayo con las crónicas culturales, hasta llegar a contar con el cuento gráfico, para comunicar su intención de narrar la ciudad para compartirla. Para crear un relato colectivo.

Empezamos a reconstruir dicha trayectoria a partir de la serie compuesta por los dos artículos, publicados en el New York Times en el pasado mes de febrero: Choque de narrativas: la cultura y el trauma en Barcelona (I) (CARRIÓN, 2018a)

y Choque de memorias: la cultura y el trauma en Barcelona (II) (CARRIóN, 2018b). En ambos textos el autor pasa revista a los acontecimientos que han colaborado a fomentar la crisis no solo política, sino más bien existencial, que 
afecta a Barcelona y, más en general, a Cataluña especialmente en el último año. Temáticas y estrategias discursivas estructuran dos artículos en que se trata de recuperar y redefinir la identidad de la capital catalana por lo que representa en la actualidad. Cierta carga de sentimentalismo emerge de las consideraciones avanzadas sobre la necesidad de reconsiderar la herencia colectiva como valor esencial para lograr la justa dosis de autoconciencia social. El compromiso del autor con los hechos contados y descritos queda patente durante la lectura de sus escritos. A nivel estructural, ambos artículos revelan el valor de la crónica con función interpretativa, aspecto sobresaliente en la evaluación del potencial narrativo expresado por la escritura periodística de Carrión.

Sin embargo, sin desatender su función informativa, las crónicas en cuestión llegan a enriquecerse de profundidad y multidimensionalidad, característica que facilita el reconocimiento de los textos en el contexto de los géneros híbridos del periodismo. Reconocemos algunos elementos que nos permiten constatar el contacto entre las dos prácticas -narrativa y periodística- como, por ejemplo, la presencia recurrente de reflexiones y contextualizaciones por parte del mismo autor, quien se hace reconocible también mediante frecuentes citas y referencias extratextuales que llegan a connotar los textos.

Las crónicas tienen un estilo impresionista en comparación con una cierta impersonalización de las noticias y de algunos reportajes porque interpretan la realidad desde un punto de vista particular, y con escasa perspectiva temporal cuando se refieren a hechos inmediatos, aunque con el aporte del propio background que posee el periodista. Este mayor nivel de interpretación da como resultado unos relatos más elaborados, con más fuentes o relaciones, con análisis y síntesis.

Casals CArro, 2005: 456

De acuerdo con las formulaciones propuestas por María Jesús Casals Carro, consideramos la crónica como el género periodístico-narrativo más interpretativo y añadimos su configuración como el terreno ideal en que el estilo del autor encaja naturalmente 1 .

Por lo que atañe a los modelos de análisis propuestos en este estudio, empezamos a presentar algunas peculiaridades que los representan, tanto a nivel temático como estructural.

La entrecruzada de los términos «narrativa» y «memoria», únicas diferencias enmarcadas en los títulos de la primera y de la segunda parte de la serie,

\footnotetext{
${ }^{1}$ Aunque en el presente texto se hace referencia a la crónica literaria como género propio de los textos analizados, no se ha podido centrar en los estudios fundamentales realizados sobre el tema de forma exhaustiva. Se señalan, por tanto, algunos de los célebres e importantes trabajos como el de L. Gomis (2008), J.L. Martínez Albertos (1993), M. Bernal RodríGuez (1997), G. Martín Vivaldi (1987), J.F. Sánchez, F. López Pan (1998), A. Grijelmo (1998), A. Chillón (2014).
} 
simbolizan perfectamente la intención del mensaje global de los textos, en que Barcelona queda reflejada histórica y actualmente como entidad espacial y cultural que alberga debates desbordantes, en ocasiones conflictivos, sobre su propia capacidad de autorrepresentación.

La hipertextualidad domina ambos textos y se impone como cifra estilística propia del autor mismo; además de representar una característica de la escritura, funciona como medio de conexión entre los géneros aludidos, a la hora de involucrar obras de arte, libros, autores y artistas diferentes como partes fundamentales del texto.

\subsection{Choques traumáticos: entre narrativa $y$ memoria}

El recurso a la experiencia de Mario, protagonista de la novela La otra parte del mundo de Juan Trejo (Tusquets, 2017) inaugura la narración periodística. El padecimiento sufrido por el protagonista de la historia, quien vuelve a Barcelona después de pasar años fuera de España para recuperarse de un duelo que pronto se revelará más mental que físico, hace de nexo para la construcción temática de este primer artículo, Choque de narrativas: la cultura y el trauma en Barcelona (I). Su crisis existencial se hace reflejo del malestar colectivo del que advierte Carrión aludiendo a la identificación de la extrañeza vivida por Mario, por motivos personales, con la que atañe a cada ciudadano catalán:

Todos los barceloneses estamos tratando de encontrar, en estos meses extraños, razones para volver a involucrarnos sentimentalmente en un proyecto que, tal vez artificialmente, sentimos como común.

CARrión, 2018a

La cuestión de la identidad comprometida es, de hecho, el argumento central de la serie y es muy interesante notar como, en esta primera parte, el discurso insiste en la exploración de las razones narrativas, mientras que en la segunda, se traza un recorrido enfocado en la recuperación de la memoria más que en la forma y en la capacidad de autorrepresentarse.

Carrión distingue tres momentos, o fases narrativas, a través de los cuales se ha constituido la identidad catalana después del franquismo hasta hoy: desde la fundación del partido político CDC, en 1976, y las peticiones de los manifestantes catalanistas, hasta el 1986 con el anuncio de los Juegos Olímpicos, en 1992, evento que supuso la renovación de la ciudad de Barcelona, para llegar, finalmente, al 2012, año en se que inaugura una nueva etapa narrativa que abrirá las puertas a un nuevo código comunicativo que definirá el lenguaje del Procés.

El pasaje de una fase de «normalización lingüística y cultural, que le hiciera contrapeso al legado de la represión franquista» a la creación de una «narrativa alternativa: la de la Ciudad Condal como espacio cosmopolita y creativo de 
influencia mundial» (CARRIóN, 2018a) ha determinado, según se dice, el fortalecimiento de posiciones basadas en la separación de ideologías y de posturas que efectivamente connotan el lenguaje y la auto-narrativa actual. La convivencia entre los «tres discursos» parece afectar a una realidad no localizada, no incluida en los límite geográficos de los Países Catalanes, porque a partir de aquel 11 de septiembre de 2012, y aún más al considerar su eco del 25 de septiembre de 2015 -día en que se celebraron las Elecciones Autonómicas con el triunfo de las voces independentistas- se ha querido representar a Cataluña como «nuevo Estado de Europa».

El autor concluye esa fase descriptiva relativa a la constitución de la identidad catalana, tan llena de citas y referencias a autores como el historiador Jordi Amat, autor de La conjura de los irresponsables, uno de los libros más valorados durante este período o a Christian Salmon y a su Storytelling. La máquina de fabricar historias y formatear mentes, evidenciando la incidencia del impacto psicológico en la construcción de cada discurso político, y apuesta por la convivencia de «los tres discursos, no solo en el interior de las fronteras de Cataluña, sino en diversos núcleos del territorio imaginario conocido como Països Catalans》 (CARrión, 2018a).

En este contexto, el autor introduce la conclusión de su discurso «más allá de las grandes retóricas sociales», desviándose hacia un plan más cultural que político y social, aportando informaciones sobre la entrega de los premios Ciutat de Barcelona; destaca el valor testimonial de la película ganadora Verano 1993, en que la cineasta Carla Simón consigue dar valor a la función de la tradición, el sentimiento de pertenencia y la autoconciencia más allá de las cuestiones conflictivas que dominan hoy día en el discurso relacional entre España y Cataluña.

Ahora bien, si la narrativa ha constituido el hilo del discurso principal de este primer artículo, veamos ahora cómo la memoria se ha hecho protagonista de la argumentación de la segunda entrega de la serie, Choque de memorias: la cultura y el trauma en Barcelona (II).

«Cultura y trauma» aparecen como los términos sugeridos tanto por el arranque del texto como por el título, rememorados por la imagen de presentación puesta al comienzo del texto. Allí se muestran los lazos amarillos colocados «en una cerca del Parque de la Ciutadela, donde se instaló una pantalla gigante para que la gente viera la sesión constitutiva del parlamento catalán, en Barcelona, el 17 de enero de 2018» (CARrión, 2018b), come reza la didascalia. La imagen resulta muy evocadora a la hora de comparar los presos políticos del Procés con las víctimas del fascismo y del nazismo, comparación formulada a raíz de la anticipación de la exposición de arte «Nazis y fascistas. La ocupación simbólica de Barcelona (1939-1945)», organizada por la Direcció de Memòria, Història i Patrimoni en colaboración con el Institut de Cultura de Barcelona en el Castel de Montjuic. La voluntad informativa con fines culturales subraya la elección del lugar de la celebración artística que no es para nada casual porque es allí que, 
en 1940, fusilaron al presidente de la Generalitat Lluís Companys; el autor aprovecha el acto histórico y la información cultural sobre el evento artístico para plantear la cuestión básica del artículo: o sea, el «proceso de resemantización de espacios fuertes» como "parte de un cambio de rumbo de la marca Barcelona. Una ciudad cuya narrativa cosmopolita se ha visto de pronto interrumpida -para el 50 por ciento- o matizada -para el otro 50 por ciento- por el procés» (CARRIÓN, 2018b). Otra vez, referencias y citas a las pinturas de artistas catalanes contemporáneos (es el caso de Francesc Torres y Francesc Abad) nos guían por el recorrido hipertextual compuesto por Carrión en búsqueda del significado $\mathrm{y}$ de las posibles modalidades de representación del trauma colectivo.

Pero la atención ahora se enfoca en los nexos existentes entre la conmemoración y la transmisión de la memoria histórica de los acontecimientos más o menos recientes.

El acento vuelve a ponerse sobre los cambios que, desde el final de la dictadura hasta hoy, han conformado la percepción identitaria catalana y, al mismo tiempo se da énfasis al «conflicto entre memoria y marca Barcelona» para mostrar las evoluciones que, con el tiempo, han influido en la manera de rendir homenaje y preservar la memoria histórica ciudadana y nacional. Buen ejemplo de esto es la referencia a otro evento artístico cultural «La herida de Hipercor. Barcelona 1987», exposición a cargo del Museo de Historia de Barcelona (MUHBA) y promovido por el Comisionado de Programas de Memoria del Ayuntamiento de Barcelona, que tuvo lugar durante cuatro meses a partir del diciembre de 2018, en memoria de las víctimas del atentado perpetrado por ETA en los almacenes Hipercor del barrio de Sant Andreu. La mención al evento conmemorativo vuelve a marcar la intención del trabajo informativo del autor, más allá de la difusión de las noticias de carácter cultural: señalar la inercia con la que se ha compensado la memoria de las víctimas de eventos trágicos, como la explosión de la bomba en el centro comercial o la persecución nazifascista, evidenciando el progreso al que asistimos en los últimos años en relación a las iniciativas de preservación de la memoria colectiva. A este propósito, pone dos ejemplos recientes y muy significativos en los que destaca el papel del MUHBA como ente propulsor de proyectos de salvaguardia del material documental ligado a acontecimientos relevantes: el atentado terrorista del 17 de agosto en la Rambla y el referéndum del 1 de octubre. En ambos casos, la recogida de documentos (grabaciones, entrevistas, artículos, fotografías, etc....) ha sido inmediata y ha contribuido de forma veraz y rigurosa a la creación de un memorial exigente y completo.

El 17 de agosto y el 1 de octubre son dos fechas históricas de significados muy distintos que corren riesgo de confusión por su cercanía en el tiempo.

Entre ambas se celebró la Diada del 11 de septiembre con las mismas rosas que pocos días antes se habían mostrado como símbolo de rechazo al terrorismo. 
Los lazos amarillos de estos meses ya fueron usados por los senadores de Convergència i Unió en 2014 para reivindicar el derecho a decidir en Cataluña.

CARRIÓN, 2018b

En este sentido, la conclusión del artículo revela la actitud autorreflexiva que necesariamente ha investido la conciencia pública catalana y ha llevado a la sociedad a encontrar la forma más adecuada para representar sus propios traumas y choques comunes.

Desde el punto de vista estructural, ambos artículos revelan estrategias similares en la construcción del discurso. Además del carácter hipertextual que los define, señalamos cierta coherencia en la organización de los datos de la refutación. Las estructuras comunicativas y las operaciones lógicas de articulación de las fases narrativas observan las pautas previstas por el género.

Es evidente la carga de narratividad de sus artículos que se configuran realmente como trabajos sometidos al proceso de elaboración narrativo-periodístico, según las modalidades de construcción mencionadas y que requieren la sucesión de las operaciones lógicas-lingüísticas del análisis, de la síntesis y de la hipótesis. Como el trabajo del periodista no se limita al suministro de datos, sino que debe velar por interpretarlos y dotar su texto de una macroestructura narrativa capaz de transmitir su valor intelectual, observamos que dicha secuencialidad le sirve al autor para lograr mayor eficacia comunicativa. De este modo, se hace evidente la prevalencia de los caracteres distintivos propios de cada modalidad narrativa periodística descrita en el marco de la crónica, según las distinciones apuntadas por María Jesús Casals Carro, del relato periodístico explicativo o mostrativo:

En todo relato periodístico, ya sea explicativo o mostrativo, el periodista debe hacer las tres operaciones que compondrán su narración: describir, secuenciar, explicar. En los reportajes o crónicas de carácter explicativo la explicación será determinante en la composición narrativa y a ella se supeditarán las descripciones y la secuenciación. Si el relato es mostrativo, por el contrario, serán la descripción y la secuenciación las operaciones protagonistas.

CASAls CARro, 2005: 461

Su prosa siempre es directa, y a la vez concéntrica: las fases del discurso parecen marcadas perfectamente, son puntuales, netas; los pasajes retóricos ceden a la exigencia narrativa necesitada por la crónica, «una crónica de viaje, esa paradoja, porque el viaje es movimiento y la escritura lo detiene, porque el viaje es siempre crónico y la crónica aspira a serlo, pero solo a veces lo consigue» (CARrión, 2017b).

En conclusión, resulta evidente la coherencia exhibida por los trabajos comentados, finalmente incluidos en el marco creativo e informativo de la crónica literaria, un género de autor en que el diálogo entre literatura y periodismo alimenta su potencia y vivifica sus potencialidades. 


\section{Conclusiones}

Si la convivencia entre estas dos artes no perjudica el valor y la eficacia peculiares de cada producto creativo, de hecho la escritura de Jorge Carrión se ofrece como buen ejemplo de hibridización artística. Su forma de pensar y de ejercer el periodismo, quedando anclado a los tejidos culturales de información y promoción de eventos e iniciativas, de la presentación de libros a exposiciones de arte, sin olvidarse de las puntuales reseñas de las mejores producciones de series televisivas internacionales, dan valor a su presencia en prensa como periodista cultural muy atento a las novedades y a los cambios que ocurren en el vasto panorama contemporáneo. Además del interés cultural, colabora en la identificación de sus trabajos la mirada literaria del escritor conocedor de las dinámicas humanas y de los territorios barridos para sus creaciones. El elemento espacial vuelve a tener un papel fundamental tanto en sus trabajos más propiamente periodísticos (como se ha visto, las dos crónicas proponen un punto de vista particular sobre la reelaboración traumática que ha implicado una redefinición del sentimiento social y espacial de la capital catalana) como en sus creaciones narrativas y ensayísticas. Hace falta recurrir, en esta fase final, al primer ejemplo de su interés activo por los espacios urbanos, es decir al cómic Barcelona. Los vagabundos de la chatarra, elaboración gráfica de carácter social en que el valor documental tiene mucho que ver con la vocación periodística de su autor.

Efectivamente, el producto final restituye el retrato de una ciudad oculta, de una sociedad marginal -la de los chatarreros y de los vagabundos- eclipsados por el fortalecimiento de la ola independentista que, al tiempo de las investigaciones llevadas a cabo por Forniés y Carrión, convulsionaba Barcelona. Los autores marcan la personalización de los personajes que aparecen durante el relato gracias al dibujo que sustituye a la cámara y que consigue aportar a la narración gráfica aún más realismo y fuerza comunicativa; por otro lado, el texto se enriquece de fuentes documentales (comunicaciones oficiales en redes sociales y páginas web oficiales, informes, etc...) y de transcripciones de diálogos en directo, sacados muy fielmente de las entrevistas, que contribuyen a fundamentar la eficacia de un reportaje en formato cómic que atestigua el estado brutal que domina en espacios bien definidos de la ciudad, como el caso de las Encants. Además, otro aspecto que eleva el rigor investigador y la potencia narrativa de la novela gráfica es la presencia de los dos autores como co-protagonistas de la narración, marca residual de procedencia tanto narrativa como periodística, por evidenciar la connotación del relato de autor, de carácter subjetivo y testimonial.

Más lejos de la esfera narrativa, encontramos otro modelo de configuración espacial en Barcelona. Libro de los Pasajes, texto en que el tono literario con- 
forma un ensayo «urbano» basado en las experiencias propias de su autor junto a la voluntad de ir más allá de las apariencias. La rememoración del pasado barcelonés se enfrenta, a través del recorrido por los pasajes, a su conformación moderna, hecha de amplios espacios abiertos a la invasión masiva. Los pasajes, más de cuatrocientos explorados por Carrión, restituyen de forma simbólica la herencia de un pasado que ha quedado oculto u olvidado tras la imponente modernización que ha investido a la capital. Una vez más el recorrido por las calles y los encuentros ocasionados por las largas sesiones de rastreo, protagonizan su percepción del espacio urbano confiriendo a la escritura un poder descriptivo unido al tono reflexivo propio de un ensayo que sabe contar el espacio interior y exterior de una ciudad. Un texto en que narrativa e investigación vuelven a estar al lado la una de la otra, coincidiendo en la perspectiva del autor animado por el descubrimiento de la cara oculta (y, otra vez, quizá olvidada) de Barcelona. La vocación periodística se revitaliza con la pasión narrativa que connota el tono de su relato, dando lugar a un valioso ejemplo de hibridación genérica que, si de un lado pone en valor las tesis asumidas por el presente trabajo, del otro subrayan la eficacia comunicativa lograda por la fusión de ambas perspectivas artísticas.

Para mí, el periodismo siempre es generosidad. Intento que el libro no sea sobre mi persona. Los protagonistas son los pasajes, pero soy quien los conecta con el todo, soy el hilo conductor, mi cuerpo que camina y mis ojos que ven. Por otro lado no creo en el mito de la objetividad del periodismo y me interesa recordar que siempre hay un sujeto que está ahí mirando, oyendo y pensando y también me interesa mucho la crónica que ensayo y el ensayo que narra, intento trabajar constantemente desde esos dos parámetros.

COROMinas I JULian, 2017

La conexión entre varios géneros de escritura posibles colabora en el reconocimiento del autor. Y el caso de Jorge Carrión nos ha permitido acceder a una panorámica de las combinaciones posibles entre varias formas y modalidades de practicar el periodismo narrativo hoy en día.

Su inclinación hacia el relato facilita la implicación narrativa en esos textos que guardan cierta atención a las inversiones cotidianas, al presente como al pasado involucrado en un espacio común que se reconoce en la ciudad.

Podríamos decir, entonces, que el periodismo narrativo es una mirada, una forma de contar y una manera de abordar las historias. Pero claro, no es un martini: nadie podría decir que sumar dos partes de un buen qué, agregarle una pizca de un gran cómo, y rematar con un autor y una aceituna darán, como resultado, una buena pieza de periodismo narrativo. 


\section{Bibliografía}

Bernal Rodríguez, Manuel, 1997: La crónica periodística. Tres aproximaciones a su estudio. Sevilla, Ed. Padilla.

CARrión, Jorge, 2017a: Barcelona. Libro de los pasajes. Barcelona, Galaxia Gutenberg.

CARrión, Jorge, 2017b: «Los perros de Capri (II): Bajo el volcán». The New York Times (sección Cultura -ed. Digital), 10.09.2017. [En línea]. https://www.nytimes.com/es/2017/09/10/losperros-de-capri-ii-bajo-el-volcan. [Fecha de consulta: 28.07.2018].

CARRIón, Jorge, 2018a: «Choque de narrativas: la cultura y el trauma en Barcelona (I)». The New York Times, 11.02.2018. [En línea]. https:/www.nytimes.com/es/2018/02/11/choque-de-narrativas-la-cultura-y-el-trauma-en-barcelona-i/. [Fecha de consulta: 29.07.2018].

CARrión, Jorge, 2018b: «Choque de memorias: la cultura y el trauma en Barcelona (II)». The New York Times, 18.02.2018. [En línea]. https://www.nytimes.com/es/2018/02/18/politicacultural-proces-barcelona-ii//. [Fecha de consulta: 29.07.2018].

Casals Carro, María Jesús, 2005: Periodismo y sentido de la realidad. Teoría y análisis de la narrativa periodistica. Madrid, Editorial Fragua.

Chillón, Albert, 2014: La Palabra Facticia. Literatura, periodismo y comunicación. Bellaterra: Universitat Autònoma de Barcelona; Castelló de la Plana: Publicacions de la Universitat Jaume I; Barcelona: Universitat Pompeu Fabra; València: Universitat de València.

Corominas i Julián, Jordi, 2017: «La ciudad escondida: Jorge Carrión y los pasajes de Barcelona». El Confidencial (sección Cultura -ed. Digital), 01.03.2017. [En línea]. https://www.elconfidencial.com/cultura/2017-03-01/jorge-carrion-barcelona-libro-de-los-pasajes_1340151/. [Fecha de consulta: 26.06.2018].

Gomis, Llorenç, 2008: Teoría de los géneros periodísticos. Barcelona, Editorial UOC.

Grijelmo, Álex, 1998: El estilo del periodista. Madrid, Taurus.

Guerreiro, Leila, 2010: «¿Qué es el periodismo literario?». Revista Anfibia (Leído en el seminario «Narrativa y periodismo», en Santander, España, desarrollado por la Fundación Santillana, la Fundación Universidad Internacional Menéndez Pelayo y el Instituto Tecnológico de Monterrey, en el año 2010). [En línea]. http://www.revistaanfibia.com/cronica/que-es-elperiodismo-literario/. [Fecha de consulta: 28.07.2018].

Herrscher, Roberto, 2012: Periodismo Narrativo. Cómo contar la realidad con las armas de la literatura. Barcelona, Publicacions i Edicions de l'Universitat de Barcelona.

Martínez Albertos, José Luis, 1993: Curso general de redacción periodística. Madrid, Paraninfo.

Martín Vivaldi, Martín, 1987: Géneros periodísticos. Reportaje, crónica y artículo. Madrid, Paraninfo.

SÁnchez, José Francisco; LóPez Pan, Fernando, 1998: «Tipología de géneros periodísticos. Hacia un nuevo paradigma». Comunicación y Estudios Universitarios, vol. 8.

SAINZ Borgo, Karina, 2015: «Jorge Carrión, el hombre que escribe novelas bajo el agua del Mar Rojo». VozPopuli, sección Cultura, 04.02.2015. [En línea]. https://www.vozpopuli. com/altavoz/cultura/Culturas-Literatura-Novelas-Ficcion-Cultura-novela-ficcion-Jorge_Carrion_0_776922333.html [Fecha de consulta: 12.06.2018].

TiJeras, Ramón, 2013: «Periodismo narrativo y no ficción». Comunicación 21, Revista científica de estudios sobre cultura y medios, $\mathrm{n}^{\mathrm{o}}$ 4. ISSN 2174-7253. [En línea]. http://comunicacion21. com/wp-content/PDF/Cuatro/Periodismo_narrativo.pdf. [Fecha de consulta: 28.07.2018]. 


\section{Nota biobibliografica}

Valeria Cavazzino ha obtenido un Doctorado en «Culturas de los países de lengua ibérica y latinoamericanas» en 2014. Sus estudios se han centrado en las relaciones entre literatura y periodismo en el mundo hispánico actual. Ha participado en varios congresos, nacionales e internacionales y actualmente tiene una beca de investigación sobre la representación de la identidad nacional española en la prensa contemporánea. 